\title{
Effects of Different Heart Positions During Off-pump Coronary Artery Bypass Surgery on Serum Ischemia Modified Albumin Level and Cardiac Output
}

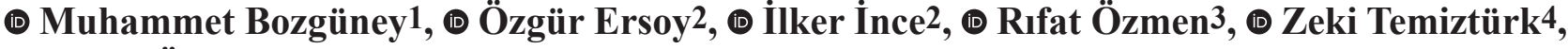 \\ (1) Kanat Özışık5, (1) Uğursay Kızıltepe²
}

\footnotetext{
1University of Health Sciences Turkey, Adana City Tranining and Research Hospital, Department of Cardiovascular Surgery, Adana, Turkey 2University of Health Sciences Turkey, Dışkapı Yıldırım Beyazıt Training and Research Hospital, Department of Cardiovascular Surgery, Ankara, Turkey

${ }^{3}$ Erciyes University Faculty of Medicine, Deparment of Cardiovascular Surgery, Kayseri, Turkey

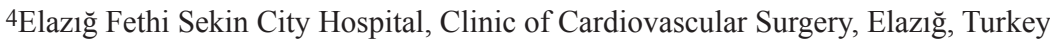

${ }^{5}$ Ankara City Hospital, Clinic of Cardiovascular Surgery, Ankara, Turkey.
}

\begin{abstract}
Objectives: We aimed to evaluate the potential effects of heart positioning during off-pump CABG (OPCAB) without a cardiac stabilizer device on serum levels of ischemia modified albumin (IMA) and cardiac output (CO).

Materials and Methods: This was a prospective study in which consecutive patients who underwent isolated OPCAB were included. Data including electrocardiography and intraarterial hemodynamic monitoring parameters were recorded. Arterial pressure waveform was analyzed. $\mathrm{CO}$ was measured for circumflex coronary artery $(\mathrm{Cx})$, diagonal coronary
\end{abstract}

Address for Correspondence: Muhammet Bozgüney, University of Health Sciences Turkey, Adana City Tranining and Research Hospital, Department of Cardiovascular Surgery, Adana, Turkey

e-mail: muhammetbozguney@hotmail.com ORCID: orcid.org/0000-0001-5650-8450

Received: 04.01.2021 Accepted: 29.01.2021

Cite this article as: Bozgüney M, Ersoy Ö, İnce İ, Özmen R, Temiztürk Z, Özışık K, Kızıltepe U. Effects of Different Heart Positions During Off-pump Coronary Artery Bypass Surgery on Serum Ischemia Modified Albumin Level and Cardiac Output. EJCM 2021;9(1):19-26.

DOI: 10.32596/ejcm.galenos.2021-01-02

${ }^{\circ}$ Copyright 2021 by Heart and Health Foundation of Turkey (TÜSAV) / E Journal of Cardiovascular Medicine published by Galenos Publishing House. 


\begin{abstract}
artery (D1), left anterior descending coronary artery (LAD), and right coronary artery (RCA) positions. Preoperative and postoperative $1^{\text {st }}, 2^{\text {nd }}, 4^{\text {th }}$, and $12^{\text {th }}$-hour blood samples were taken for serum ischemia modified albumin measurements.

Results: Forty patients who underwent OPCAB were included in the study. The mean age was $60.3 \pm 10.2$ years. Hospital mortality, stroke, postoperative myocardial infarction, acute kidney injury, sternal infection, and re-operation for bleeding/ tamponade were not observed postoperatively. Six patients (15\%) who developed postoperative atrial fibrillation (AF) had a significantly higher mean serum IMA level compared with patients who did not. There was no statistically significant difference in preoperative and postoperative mean serum IMA levels $(\mathrm{p}=0.925)$. Mean $\mathrm{CO}$ values measured at four different heart positions were not significantly different from each other except for a difference between LAD and $\mathrm{Cx}(\mathrm{p}=0.002)$.

Conclusion: Our results showed that when the heart was in the $\mathrm{Cx}$ anastomosis position, the $\mathrm{CO}$ was significantly lower than the LAD position; however, there was no significant serum IMA raise despite CO decrease. IMA levels did not change significantly from baseline values. Patients who developed postoperative AF had higher IMA levels than patients who did not develop AF.
\end{abstract}

Keywords: Atrial fibrillation, cardiac ischemia, cardiac output, ischemia modified albumin, off-pump coronary artery bypass

\section{Introduction}

Coronary artery bypass grafting is a common surgical procedure for multi-vessel atherosclerotic patients, which can be performed while the heart is still beating off-pump) or with cardioplegia (on-pump) ${ }^{(1-3)}$. Several studies have shown that off-pump cardiac bypass surgery (OPCAB) is associated with less cardiac injury and systemic inflammation compared to on-pump coronary artery bypass grafting (CABG). Moreover, these molecular changes can lead to clinical outcomes such as lower complication rates, lower mortality rates, and shorter hospital stays in favor of $\mathrm{OPCAB}^{(2,4,5)}$. However, $\mathrm{OPCAB}$ is not always innocent of myocardial injury ${ }^{(6)}$, and generally is criticized for its inability for extensive revascularizations. These limitations prompted the use of cardiac stabilizers but that may have negative consequences in terms of systemic hemodynamics.

Postoperative myocardial ischemia is one of the most common factors that cause the development of postoperative myocardial infarction (MI), which is seen between $3 \%$ and $20 \%$ of CABG patients ${ }^{(7-9)}$. Detecting and monitoring ischemia before irreversible tissue damage occurs as in postoperative MI should be one of the most important goals. Several myocardial injury markers, including troponin I, Heart-Type Fatty AcidBinding Protein, choline, and others, are being used for this purpose ${ }^{(10-12)}$.

Ischemia modified albumin (IMA) is generated by the modulation of the tertiary structure of the albumin molecule by reactive oxygen species during ischemia ${ }^{(10)}$. Several studies up to now have demonstrated the efficacy of serum IMA levels for early detection of ischemia in various settings, including acute coronary syndrome and postoperative $\mathrm{MI}^{(13,14)}$. However, data regarding the utility of serum IMA for the detection of ischemia during OPCAB are insufficient ${ }^{(15,16)}$.

Clinical experiences point to the deleterious effects of cardiac stabilizing devices used during OPCAB. These should be taken with regard to the beneficial effects obtained with OPCAB. Dong et al. ${ }^{(16)}$ evaluated the role of serum IMA levels in patients undergoing OPCAB in which a cardiac stabilizer was used. Thus, we aimed to investigate serum IMA levels and the alterations in cardiac output (CO) when the heart was temporarily suspended 
at various positions during $\mathrm{OPCAB}$ procedures without cardiac stabilizer.

\section{Materials and Methods}

Our study was a prospective study that primarily investigated the effects of different surgical positions of the heart provided by simple suspension sutures during isolated off-pump coronary artery bypass surgery on serum ischemia modified albumin levels and CO. The study was performed at Dışkapı Yıldırım Beyazıt Training and Research Hospital between February 2011 and June 2011. The Ethics Committee of Dışkapı Yıldırım Beyazıt Training and Research Hospital approved the study protocol (approval number: 27, date: 17/08/2011), and all patients provided written informed consent before enrolment in the study. The study was performed in compliance with the Helsinki Declaration.

The consecutive patients who were scheduled to undergo isolated off-pump CABG (OPCAB) were included in the study, irrespective of the number and localization of the atherosclerotic coronary artery. The indications for CABG were determined by a committee involving cardiologists and cardiac surgeons. Patients with the following features were excluded: requirement for emergency surgery, acute MI, on-pump CABG, additional cardiac pathology rather than coronary artery disease requiring intervention such as valve lesions, chronic kidney disease, liver disease, incurable malignancy, cerebrovascular accident, systemic infections and low preoperative serum albumin level.

All patients underwent routine preparation phase for the $\mathrm{CABG}$ operation, which was standard at our institution. Intraoperative data including electrocardiography, intraarterial blood pressure, central venous pressure, oxygen saturation obtained with pulse oximetry, urine output, and body temperature were monitored and recorded. Arterial pressure waveform (APW) was analyzed (Flotrac Sensor System, Edwards Lifesciences, Irvine CA, USA). CO was measured noninvasively for 12 hours. $\mathrm{CO}$ and the length of stay of the measurement sensor at the respective position were measured for circumflex coronary artery $(\mathrm{Cx})$, diagonal coronary artery (D1), left anterior descending coronary artery (LAD) and right coronary artery (RCA).

Several venous blood samples were obtained for the measurement of serum IMA levels. The first sample was taken before the induction of anesthesia (first measurement). Subsequent blood samples were obtained in a serum separator at postoperative $1^{\text {st }}, 2^{\text {nd }}, 4^{\text {th }}$ and $12^{\text {th }}$ hour time points (second, third, fourth and fifth IMA measurements, respectively). After 30 minutes, the clotted samples were centrifuged for 15 minutes at $1,000 \mathrm{~g}$. All serum samples were kept at $-20^{\circ} \mathrm{C}$ until analysis and being centrifuged again after thawing before its use in the assay. The serum IMA levels were analyzed using the Cusabio Biotech human IMA ELISA kits (catalog number: CSBE09594h, USCN, Houston, TX, USA).

The logistic version of the European System for Cardiac Operative Risk Evaluation (Log-EuroSCORE) was calculated to predict operative mortality ${ }^{(17)}$. EuroSCORE incorporates patient, cardiac and operation related risk factors to produce an overall risk score. In the logistic version, the same risk factors are used.

\section{Surgical Procedure}

Anesthesia induction was performed using propofol (3-4 $\mathrm{mg} / \mathrm{kg} /$ hour), thiopental (3-5 $\mathrm{mg} / \mathrm{kg}$ ), or fentanyl citrate $(5-10 \mu \mathrm{g} / \mathrm{kg})$. Maintenance of anesthesia was achieved with propofol, fentanyl or sevoflurane at low concentrations. Unfractionated heparin of 5,000 U was administered to all patients during internal thoracic artery harvesting and the same dose was re-administered when apparent coagulation was observed at the operation site. Median sternotomy was performed. Left internal mammary artery (LIMA), radial artery, and saphenous vein grafts depending on the coronary anatomy were prepared simultaneously. The targeted intraoperative heart rate was $50-70$ beats per minute. The heart rate was controlled by the application of beta-blockers, namely, esmolol or metoprolol. Systolic blood pressure was maintained at $50-70 \mathrm{mmHg}$ during the distal anastomosis. 
Patients were placed into Trendelenburg position and the dose of the inhaled anesthetic was adjusted to keep the systolic blood pressure within the target range. Neither intracoronary shunts nor commercial stabilizer devices were used in any of the operations. During the surgery, stabilization of target coronary arteries was achieved via simple radial traction sutures as described elsewhere ${ }^{(18)}$. During the creation of distal anastomoses, bleeding arising from the target coronary artery was controlled with atraumatic bulldog clamps. The proximal anastomosis of the radial artery graft was performed on LIMA in eligible patients, and in the rest of the patients, the ascending aorta with a side-clamp was used for this purpose.

After the construction of the anastomosis, a bleeding check was made, epicardial pacing wires and thorax drains were placed. Thereafter, sternum was closed and the patient was transported to the surgical ICU.

All patients were administered metoprolol $50 \mathrm{mg} / \mathrm{day}$, acetylsalicylic acid $300 \mathrm{mg} /$ day, and clopidogrel $75 \mathrm{mg} /$ day postoperatively unless a contraindication was present. Patients whose conditions were stable were transported to the surgical ward and discharged when appropriate.

\section{Statistical Analysis}

One-way analysis of variance (ANOVA) was used to compare the $\mathrm{CO}$ values measured in LAD, D1, Cx, and RCA positions of the patients, and the Tukey test was used for binary comparisons for statistically significant parameters. In the analysis of the changes in the IMA values in post-operative measurements, repeated measures ANOVA was used if the test assumptions were met, and the Friedman test was used if the assumptions were not met. Multivariable regression analysis and the Pearson correlation analysis were used to investigate the effect of $\mathrm{CO}$ values measured at four positions of the heart and the IMA levels. The Kruskal-Wallis H statistical analysis was used in the comparison of $\mathrm{CO}$ at four different positions and IMA level according to the number of grafts. Statistical analysis was performed using SPSS 16 Statistical Package for Social Sciences (SPSS Inc. Released 2007. SPSS for
Windows, Version 16.0. Chicago). A p-value lower than 0.05 was considered statistically significant.

\section{Results}

Forty patients who underwent elective, isolated, primary CABG with the off-pump technique were included in the study. There were 10 (25\%) women and 30 (75\%) men. The mean age of the patients was $60.3 \pm 10.2$ years. The mean Log-EuroSCORE and left ventricle ejection fraction (LVEF) of the patients were (4.62 \pm 6.73$)$ and (44.6 $\pm 5.3 \%)$, respectively. Hospital mortality, stroke, postoperative MI, acute kidney injury, sternal infection, and re-operation for bleeding/tamponade were not observed postoperatively in any of the patients. None of the patients required intraaortic balloon pump and conversion from OPCAB to CABG with cardiopulmonary bypass due to hemodynamic instability. Atrial fibrillation (AF) was seen in $6(15 \%)$ patients postoperatively. The mean length of stay in the intensive care unit (ICU) and the hospital were 2.02 \pm 1.4 and $6.5 \pm 2.0$ days, respectively. The clinicodemographic characteristics and perioperative features of the entire study population are presented in Table 1 .

There was no statistically significant difference in preoperative and postoperative mean serum IMA levels ( $\mathrm{p}=0.925)$ (Table 2 and Figure 1). Postoperative IMA values measured at $1^{\text {st }}, 2^{\text {nd }}, 4^{\text {th }}$, and $12^{\text {th }}$ hours were not significantly different from each other and mean preoperative IMA value. There was no significant correlation between the mean serum IMA level and LogEuroscore, LVEF, number of grafts, length of operation, postoperative hemoglobin level, and length of ventilation.

The mean $\mathrm{CO}$ values measured in four different positions of the heart were not significantly different from each other except the difference between LAD and $\mathrm{Cx}$ (Table 3 and Figure 2). The mean CO was $3.44 \pm 0.76 \mathrm{~L} /$ minute at $\mathrm{LAD}$ position, and $2.80 \pm 0.48 \mathrm{~L}$ /minute at $\mathrm{Cx}$ position $(\mathrm{p}=0.002)$. None of the $\mathrm{CO}$ values measured at different positions was correlated with age, LVEF, LogEuroscore, length of operation, and serum IMA levels. 
Table 1. Clinicodemographic characteristics and perioperative features of the entire study population

\begin{tabular}{|l|l|}
\hline Parameters & $\begin{array}{l}\text { Variable valu } \\
\text { [n (\%) or m }\end{array}$ \\
\hline Preoperative data & \\
\hline Age (years) & $60.3 \pm 10.2$ \\
\hline Sex (male) & $30(75 \%)$ \\
\hline Body mass index $\left(\mathrm{kg} / \mathrm{m}^{2}\right)$ & $26.12 \pm 4.33$ \\
\hline Peripheral vascular disease & $2(5 \%)$ \\
\hline Diabetes mellitus & $15(37 \%)$ \\
\hline Hypertension & $32(80 \%)$ \\
\hline Hyperlipidemia & $13(32 \%)$ \\
\hline COPD & $11(27 \%)$ \\
\hline Smoking history & $24(60 \%)$ \\
\hline Cerebrovascular disease & 0 \\
\hline LogEuroScore & $4.62 \pm 6.73$ \\
\hline LVEF & $44.6 \pm 5.3 \%$ \\
\hline
\end{tabular}

\section{Operative data}

Conversion to $\mathrm{CPB}$

0

Number of bypassed vessel

$3(7 \%)$

CABGx1

$12(30 \%)$

CABG $\times 2$

$13(33 \%)$

CABG $\times 3$

$12(30 \%)$

CABG $\times 4$

0

IABP

$287.30 \pm 72.06$

Mean skin-to-skin OR time (minutes)

Postoperative data

Hospital mortality

0

Postoperative MI

0

Atrial fibrillation

$6(15 \%)$

Stroke

0

Chronic kidney disease

0

Re-operation for bleeding/tamponade

0

Sternal infection

0

Length of ICU stay (days)

$2 \pm 0.45$

Length of hospital stay (days)

$6.49 \pm 0.93$

CABG: Coronary artery bypass grafting, COPD: Chronic obstructive pulmonary disease, CPB: Cardiopulmonary bypass, IABP: Intraaortic balloon pump support commenced at perioperative period only, ICU: Intensive care unit, LVEF: Left ventricular ejection fraction, MI: Myocardial infarction, OR: Operating room, SD: Standard deviation
The mean $\mathrm{CO}$ values at four different positions and mean IMA levels were not significantly different in patients who underwent $1^{\text {st }}, 2^{\text {nd }}, 3^{\text {rd }}$, and ${ }^{\text {th }}$ vessel CABG.

The only observed complication during the postoperative follow-up was AF in six patients (15\%). The patients who developed postoperative AF had significantly higher mean serum IMA level compared to patients who did not (Table 4).

\section{Discussion}

The feature results of our study were as follows:

$\mathrm{CO}$ measured at the position of LAD anastomosis was significantly higher than in the $\mathrm{Cx}$ position. Patients who developed postoperative AF had higher IMA levels than those who did not develop AF.

Table 2. Median serum IMA values at preoperative and several postoperative time points $(n=40)$

\begin{tabular}{|c|c|c|}
\hline & IMA & p-value \\
\hline Pre-operative & $92.4(91.7-94.3)$ & \multirow{5}{*}{0.907} \\
\hline Post- operative ( $1^{\text {st }}$ hour) & $92.4(92-94.9)$ & \\
\hline Post- operative ( $2^{\text {nd }}$ hour) & $93.6(91.8-95.4)$ & \\
\hline Post- operative (4th hour) & $93.1(91.8-95.3)$ & \\
\hline Post- operative (12 ${ }^{\text {th }}$ hour) & $93.4(91.8-95.1)$ & \\
\hline
\end{tabular}

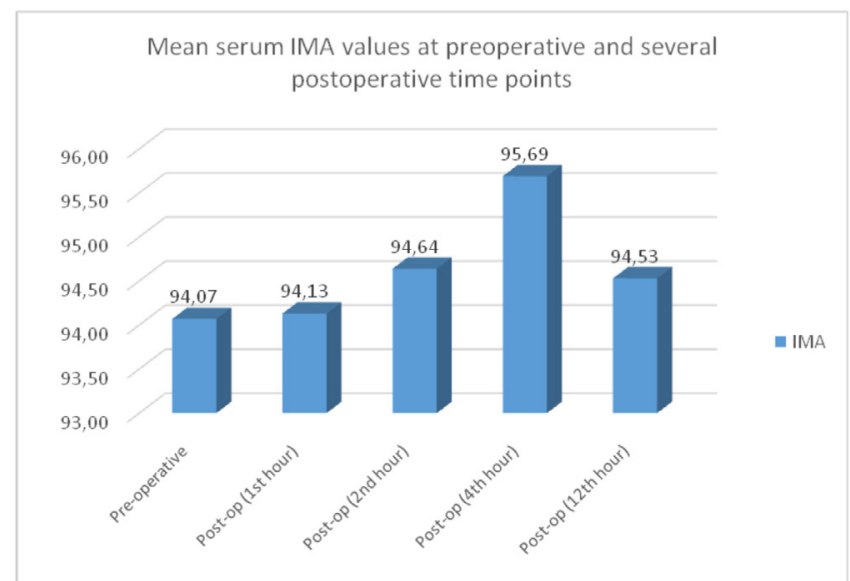

Figure 1. Mean serum IMA values at preoperative and several postoperative time points

IMA: Ischemia modified albumin, Post-op: Post-operative 
One of the most important disadvantages of OPCAB surgery is its lack of capacity for performing extensive revascularization procedures mainly due to the hemodynamic instability caused by changing the positions of the heart ${ }^{(19,20)}$. On the other hand, using stabilizer devices may extend the duration of the operation and cumbersome to use. Therefore, we did not use stabilizer devices in OPCAB operations in this study. We sought to answer the question of whether different positionings of the heart during OPCAB without a stabilizer device had any bearings on the CO. In addition, we attempted to evaluate whether any potential decrease in $\mathrm{CO}$ led to ischemia that we measured via IMA levels in this study.

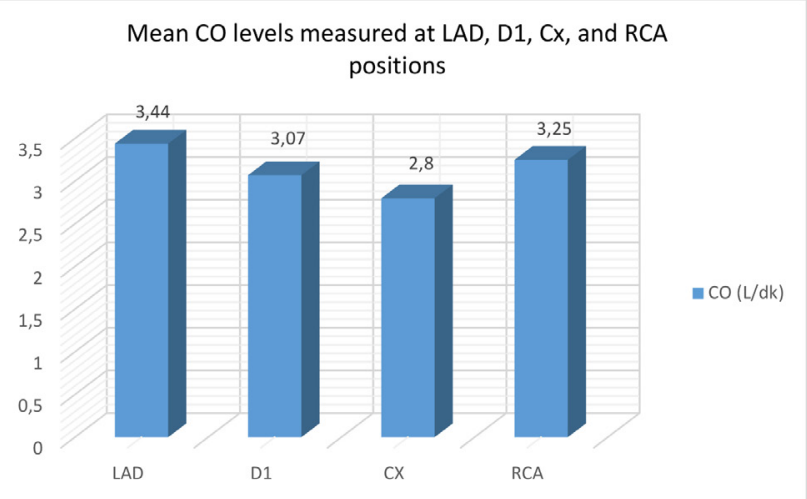

Figure 2. Mean CO levels measured at LAD, D1, Cx, and RCA positions

CO: Cardiac output, LAD: left anterior descending coronary artery, D1: Diagonal coronary artery, Cx: Circumflex coronary artery, RCA: Right coronary artery
Dong et al. ${ }^{(16)}$ assessed the level of IMA in patients who underwent $\mathrm{OPCAB}$. The authors found that serum IMA level reached peak values immediately after surgery, then gradually regressed, finally was significantly higher than the baseline levels during the first $24 \mathrm{~h}$ after OPCAB in all 63 patients. Ten patients $(16 \%)$ had postoperative MI. The patients who developed postoperative MI had significantly higher IMA levels than those without postoperative MI at 3 hours after CABG. Moreover, in both groups, serum IMA levels were significantly higher compared to baseline values. In another study conducted with patients who underwent $\mathrm{OPCAB}$, the authors evaluated the relationship between IMA and MI. They observed perioperative MI in eight patients (16\%) out of 50 study participants. The IMA levels of the postoperative MI group at 30 minutes and at three, six, and 12 hours after declamping were found significantly higher than the patients who did not develop postoperative MI. Additionally, the IMA levels at 30 minutes after aortic cross-clamping were higher than the baseline IMA levels in both groups ${ }^{(13)}$.Our study was not in agreement with the findings of these two studies. First, we did not observe any postoperative MI in our study cohort. Second, the serum IMA levels were comparable throughout the study at different time points.

Interpositional $\mathrm{CO}$ comparisons detected significant difference only between $\mathrm{Cx}$ and LAD cardiac positions (lower in $\mathrm{Cx}$ ) $(\mathrm{p}=0.002)$ In our study, compared to the previous studies, postoperative serum IMA levels did not

Table 3. Comparison of mean $\mathrm{CO}$ values measured in four different positions of the heart

\begin{tabular}{|c|c|c|c|c|c|}
\hline & LAD $(n=40)$ & D1 $(n=20)$ & $C X(n=29)$ & $\operatorname{RCA}(n=25)$ & p-value \\
\hline $\mathrm{CO}(\mathrm{L} / \mathrm{dk})$ & $3.44 \pm 0.7553$ & $3.07 \pm 0.6255$ & $2.80 \pm 0.4801$ & $3.25 \pm 0.6811$ & $0.003^{*}$ \\
\hline
\end{tabular}

CO: Cardiac output, Cx: Circumflex, D1: Diagonal 1, LAD: Left anterior descending, RCA: Right coronary artery, $n$ : Number

*There was only one significant intergroup difference between $L A D$ and Cx (Tukey post-hoc test, $p=0.002$ )

Table 4. IMA levels in patients with and without postoperative atrial fibrillation

\begin{tabular}{|l|l|l|l|}
\hline & \multicolumn{2}{c|}{ Atrial fibrillation (AF) } \\
\hline & $\begin{array}{l}\text { AF }(-) \\
(\mathbf{n = 3 4 )}\end{array}$ & $\begin{array}{l}\text { AF }(+) \\
(\mathbf{n}=\mathbf{6})\end{array}$ & p-value \\
\hline IMA (Mean \pm SD) & $93.7 \pm 2.4$ & $99.4 \pm 5.5$ & 0.011 \\
\hline
\end{tabular}

IMA: Ischemia modified albumin, SD: Standard deviation, $n$ : Number, AF: Atrial fibrillation 
show any change from baseline. However, most studies reported increased IMA levels after cardiac surgery even in patients without postoperative $\mathrm{MI}^{(21,22)}$. This was also detected even in patients who underwent off-pump bypass surgery.

Kanko et al. ${ }^{(22)}$ studied the prognostic value of serum IMA levels in patients undergoing CABG. Sixteen out of thirty patients (53\%) developed paroxysmal AF after surgery. The mean serum IMA levels in these patients was found to be significantly higher than in those who did not develop AF. Up to current clinic data, our study is the second study confirming this preliminary result. In our study, six patients (16\%) developed AF postoperatively and the mean IMA levels of these patients were significantly higher than those of patients without postoperative AF. Regarding the potential predictive role of serum IMA levels for the development of postoperative $\mathrm{AF}$, further studies are required.

\section{Study Limitations}

There are some limitations in this study, which deserve to be mentioned: First, our sample size was relatively small. Second, apart from six patients with postoperative AF, the postoperative course was uneventful for the majority of the patients; in other words, the study population did not have any ischemic event such as postoperative MI. We did not have any patients with postoperative MI in contrast to the most reported studies. This fact might have led to unchanged postoperative serum IMA levels compared to baseline serum IMA levels. In addition, it would have been better if we had studied other markers of myocardial injury and ischemia. Measuring serum IMA levels is more effective in early detection of ischemia than other established markers. Despite these limitations, to our knowledge, this is the first study in the literature reporting the effect of OPCAB without stabilizing device on $\mathrm{CO}$ and serum IMA levels.

\section{Conclusion}

This is the first study evaluating OPCAB without a stabilizing device on $\mathrm{CO}$ along with serum IMA levels as a marker of ischemia. Our results showed that when the heart was in $\mathrm{Cx}$ anastomosis position, the $\mathrm{CO}$ was significantly lower than LAD position; however, there was no significant serum IMA increase despite $\mathrm{CO}$ decrease. Interestingly, patients who developed postoperative AF had higher IMA levels than patients who did not develop AF. Our results revealed favorable effects of OPCAB on hemodynamics and ischemia, which is quite common during bypass surgery.

\section{Ethics}

Ethics Committee Approval: The Ethics Committee of Dışkapı Yıldırım Beyazıt Training and Research Hospital approved the study protocol (approval number: 27, date: 17/08/2011).

Informed Consent: All patients provided written informed consent before enrolment in the study.

Peer-review: Externally peer-reviewed.

\section{Authorship Contributions}

Surgical and Medical Practices: M.B., Ö.E., İ.İ., Z.T., K.Ö., U.K., Concept: M.B., Ö.E., K.Ö., U.K., Design: M.B., U.K., Data Collection or Processing: M.B., Ö.E., Z.T., K.Ö., Analysis or Interpretation: M.B., R.Ö., U.K., Literature Search: M.B., Ö.E., İ.İ., R.Ö., Z.T., K.Ö., U.K., Writing: M.B., İ.İ., R.Ö.

Conflict of Interest: The authors are declaring to have no conflict of interest.

Financial Disclosure: The study was supported by Dışkapı Yıldırım Beyazıt Training and Research Hospital Scientific Studies Support Board.

\section{References}

1. Schulze C, Conrad N, Schütz A, et al. Reduced expression of systemic proinflammatory cytokines after off-pump versus conventional coronary artery bypass grafting. Thorac Cardiovasc Surg 2000;48:364-9.

2. Aklog L. Future technology for off-pump coronary artery bypass (OPCAB). Semin Thorac Cardiovasc Surg 2003;15:92-102.

3. Shroyer AL, Hattler B, Wagner TH, et al. Five-Year Outcomes after OnPump and Off-Pump Coronary-Artery Bypass. N Engl J Med 2017;377:62332.

E Journal of Cardiovascular Medicine | Volume 9 | Issue 1 | 2021 
4. Ascione R, Caputo M, Calori G, Lloyd CT, Underwood MJ, Angelini GD. Predictors of atrial fibrillation after conventional and beating heart coronary surgery: A prospective, randomized study. Circulation 2000;102:1530-5.

5. Hannan EL, Wu C, Smith CR, et al. Off-pump versus on-pump coronary artery bypass graft surgery: differences in short-term outcomes and in long-term mortality and need for subsequent revascularization. Circulation 2007;116:1145-52.

6. Paparella D, Cappabianca G, Malvindi P, et al. Myocardial injury after offpump coronary artery bypass grafting operation. Eur J Cardiothorac Surg 2007;32:481-7.

7. McFalls EO, Ward HB, Moritz TE, et al. Predictors and outcomes of a perioperative myocardial infarction following elective vascular surgery in patients with documented coronary artery disease: results of the CARP trial. Eur Heart J 2008;29:394-401.

8. Järvinen O, Julkunen J, Saarinen T, Laurikka J, Huhtala H, Tarkka MR. Perioperative myocardial infarction has negative impact on health-related quality of life following coronary artery bypass graft surgery. Eur J Cardiothorac Surg 2004;26:621-7.

9. Dahlin LG, Olin C, Svedjeholm R. Perioperative myocardial infarction in cardiac surgery--risk factors and consequences. A case control study. Scand Cardiovasc J 2000;34:522-7

10. Mair J, Hammerer-Lercher A. Markers for perioperative myocardial ischemia: what both interventional cardiologists and cardiac surgeons need to know. Heart Surg Forum 2005;8:319-25.

11. Lin S, Yokoyama H, Rac VE, Brooks SC. Novel biomarkers in diagnosing cardiac ischemia in the emergency department: a systematic review. Resuscitation 2012;83:684-91.

12. Singh V, Martinezclark P, Pascual M, Shaw ES, O'Neill WW. Cardiac biomarkers - the old and the new: a review. Coron Artery Dis 2010;21:24456.

13. Mentese U, Dogan OV, Dogan S, et al. The relationship between ischemiamodified albumin and myocardial infarction in on-pump coronary artery bypass grafting. Türk Göğüs Kalp Damar Cer Derg 2015;23:245-50.
14. Oran I, Oran B. Ischemia-Modified Albumin as a Marker of Acute Coronary Syndrome: The Case for Revising the Concept of "N-Terminal Modification" to "Fatty Acid Occupation" of Albumin. Dis Markers 2017;2017:5692583.

15. Wang H, Lyu Y, Liao Q, et al. Effects of Remote Ischemic Preconditioning in Patients Undergoing Off-Pump Coronary Artery Bypass Graft Surgery. Front Physiol 2019;10:495.

16. Dong SY, Wang XJ, Xiao F, Wang J, Li YF, Li Y. Detection of perioperative myocardial infarction with ischemia-modified albumin. Asian Cardiovasc Thorac Ann 2012;20:252-6.

17. Roques F, Nashef SA, Michel P, et al. Risk factors and outcome in European cardiac surgery: analysis of the EuroSCORE multinational database of 19030 patients. Eur J Cardiothorac Surg 1999;15:816-22.

18. Kurtoglu M, Ates S, Demirozü T, Duvan I, Karagoz HY, Aybek T. Facile stabilization and exposure techniques in off-pump coronary bypass surgery. Ann Thorac Surg 2008;85:30-1.

19. Gründeman PF, Borst C, van Herwaarden JA, Mansvelt Beck HJ, Jansen EW. Hemodynamic changes during displacement of the beating heart by the Utrecht Octopus method. Ann Thorac Surg 1997;63:88-92.

20. Mathison M, Edgerton JR, Horswell JL, Akin JJ, Mack MJ. Analysis of hemodynamic changes during beating heart surgical procedures. Ann Thorac Surg 2000;70:1355-60.

21. Thielmann M, Pasa S, Holst T, et al. Heart-Type Fatty Acid Binding Protein and Ischemia-Modified Albumin for Detection of Myocardial Infarction After Coronary Artery Bypass Graft Surgery. Ann Thorac Surg 2017;104:130-7

22. Kanko M, Yavuz S, Duman C, Hosten T, Oner E, Berki T. Ischemiamodified albumin use as a prognostic factor in coronary bypass surgery. $\mathrm{J}$ Cardiothorac Surg 2012;7:3. 